\title{
'I'm not a therapist you know... I'm an artist': Facilitating well-being and basic psychological needs satisfaction through community arts participation
}

\author{
Rachel Swindells, Rebecca Lawthom, Clive Parkinson, Ornette Clennon and Carolyn \\ Kagan, Manchester Metropolitan University Christophe de Bézenac, University of \\ Liverpool
}

\begin{abstract}
The role of the artist is crucial to the success of arts for health initiatives yet remains underexplored in the research literature. This article examines the practice of arts facilitation through the lens of self-determination theory (SDT). Fourteen interviews with artists leading projects for older adults across three settings were subject to a secondary thematic analysis. A hybrid approach was adopted with themes developed inductively and deductively. Artists were found to satisfy participants' basic psychological needs in diverse ways. Autonomy: artists spoke of valuing the expression of individual differences and identities, encouraging participants to assume ownership of projects. Competence: developing participants' aptitudes and skills and repairing negative self-beliefs emerged as common goals. Relatedness: artists sought to cultivate social interaction within groups and forge relationships with participants themselves. Self-determination theory provides a well-validated framework to conceptualize the psycho-social processes mediating arts project outcomes relating to psychological wellbeing.
\end{abstract}

\section{Keywords}

community arts

arts facilitation 
arts practice

psychological well-being

self-determination theory

basic needs

\section{Introduction}

Although a growing body of evidence indicates that arts participation may help improve and maintain health and well-being across the lifespan, there have been calls for research to identify the processes through which interventions work. Understanding the mechanisms mediating observed outcomes is seen as key to advancing theory and practice (Lawthom et al. 2007; Clift et al. 2009). One component of arts schemes recognized as requiring more scrutiny is the contribution of the artist as project facilitator. With some noteworthy exceptions (e.g. Raw 2013; Van Lith et al. 2009; Horne 2016), the nature of this role has been overlooked in favour of outcomes-focused research (Stickley et al. 2016). This is despite acknowledgement that the manner in which activities are planned and delivered impacts on the effectiveness of any given scheme (White 2006; Camic 2008). Ultimately it is the artist who animates a project - hence the associated term animateur. With a sense of a living person in mind, the artist has been described as the 'fundamental dynamic catalyst' (Raw 2013: 312) in a session; the person who 'activates the workshop event' (Higgins 2008: 327). As such it is suggested the benefits of arts participation may lie as much in the interactions between leader and participants as arts practice per se (Creech et al. 2012). Thinking through the relationships between the aesthetic and social dimensions of participatory arts work is therefore essential to theorizing the links between outputs and outcomes. 
The current study contributes to the discussion by exploring the role of the artist facilitator through the lens of self-determination theory (SDT) (Ryan and Deci 2001). Specifically it uses a central component of SDT, basic needs theory, as a frame in which to interpret artists' accounts of their work and understandings of the connections between arts practice and psychological health. Drawing on qualitative data from arts projects for older adults in health care and community settings the following questions are addressed: how do artists articulate this work - what are the values and approaches informing their practice? How does arts facilitation help to satisfy and/or thwart basic psychological needs?

\section{The artist as facilitator}

The term arts facilitator as used here refers to artists of all specialisms delivering participatory arts projects outside of formal education programmes or clinical work. These may range from one-off workshops to longer-term schemes taking place in diverse settings and with wide-ranging populations. In the UK context, the practice of arts facilitation is often traced back to the community arts movement of the late 1960s, which challenged elitist notions about access and ability (Cole 2011). The field is further indebted to humanistic psychology with its notion that personal growth and creativity are central to human health across the lifespan (Van Lith et al. 2009). While a number of alternatives to the term facilitator are in use (e.g. community artist, artist-in-residence, visiting artist, arts practitioner) many artists working in community/health settings are keen to point out that they are neither arts teachers nor therapists. Indeed community arts practice seems to be commonly defined by what it is not: formal education or therapy. With reference to the former, some individuals are attracted to community arts because they feel conventional arts education has failed to meet the needs of socially disadvantaged populations. There may also be a resistance to the notions of authority, assessment and competition perceived to underpin 
traditional western arts pedagogies (Veblen 2009). Even so, Creech et al. (2012) observe that experienced facilitators shift between styles of transmission, combining standard teaching techniques such as didactic modelling alongside participant-led methods.

Arts facilitators also position themselves as distinct from arts therapists by pointing to their own focus on artistic processes and content, as opposed to psychotherapeutic outcomes (Broderick 2011; Moss and O’Neill 2009). The literature suggests that many artists view well-being benefits as secondary to and emerging from the satisfactions and challenges of arts practice itself (Lawthom et al. 2007; Brown 2006). While arts therapists may plan an intervention with an individual's medical history in mind, arts facilitators tend to have little information about a participant's health status (at least at the beginning), sometimes perceiving this to be an advantage to building non-hierarchical relationships without preconceived understandings (Brett et al. 2011). Although there is an inevitable overlap between approaches (Clennon 2013), it should be noted that arts therapies in the United Kingdom are governed by national regulatory bodies and can only be practised by graduates of accredited training programmes. Still, the differences between methods are not always well articulated and some commenters have argued there needs to be a greater clarity regarding the distinct skill sets that artists, arts therapists and arts educators bring (Moss and O'Neill 2009). Such discussions form part of a wider debate around professionalization and the question of whether arts facilitators should be subject to statutory training requirements and regulation. On one side are claims that professionalizing practice is essential for reasons of participant safety, quality assurance but also raising the status of and protecting artists (Dileo and Bradt 2009). On the other are concerns about the homogenization of creative practices in a domain that sees adaptation to local contexts as a strength (Raw 2013; Hughes 2005). Some professionalization is already in evidence in the advent of training courses, practitioner and 
research networks, conferences, academic journals and voluntary codes of practice (see, e.g., http://www.soundsense.org).

What is undisputed is that leading participatory arts projects demands multiple competencies beyond arts-specific expertise. There is a requirement, for example, for artists to: put people at ease and make sessions enjoyable; accommodate participants with wide-ranging abilities and needs; and to help bring about the social, educative, and/or health and well-being outcomes demanded by funders and other stakeholders. Artists' accounts emphasize the fluidity inherent in the role as they shift their approach from one project, session or moment within a session to the next. Price compares his multi-functional position as a community musician as being akin to a 'human version of a Swiss pen-knife' as he switches between 'lecturer, facilitator, youth worker, confidant, advisor technician and child-minder' (2010: 332). Considering such broad skills as deployed in the act of arts facilitation is essential to conceptualizing participant benefits and identifying mechanisms of change.

\section{Theorizing well-being}

Models of well-being in psychology tend to fall into one of two main camps. Hedonic wellbeing is viewed as synonymous with happiness and pleasure, and the avoidance of pain (Diener 1984; Keyes et al. 2002), while eudaimonic theories emphasize personal development, social connectivity and purposeful living over the longer-term (McGregor and Little 1998; Ryan and Deci 2000). It has been suggested elsewhere that there is an inherent compatibility between eudaimonic accounts of well-being and community arts practice. Both embrace humanistic ideas connecting health and personal growth, and recognize that painful emotions are not just to be avoided but might represent a sane response to a difficult situation (Swindells et al. 2013). The eudaimonic framework used in this study is SDT (Ryan and Deci 
2001), a conceptual model also previously found to be consistent with the processes outlined by artists in relation to improved participant well-being (Kelaher et al. 2007).

SDT is a macro-theory of motivation and well-being that specifies the conditions an environment must supply in order for people to flourish (Ryan and Deci 2001). The theory emphasizes that innate growth-orientated tendencies essential for psychological health (in the eudaimonic sense), do not function automatically but require specific social nutrients and supports (Gagné and Deci 2005). As such, it is particularly relevant to the study of arts facilitation because it provides not only a congruent definition of well-being but also identifies the means by which a particular activity or mode of delivery might promote or curb well-being outcomes. SDT contends that there are three basic psychological needs autonomy, competence and relatedness - with all three requiring satisfaction for optimal mental health (Ryan and Fredrick 1997). Autonomy is defined as the experience of selfgovernance, volition and the feeling that behaviour emanates from the self in accordance with self-endorsed values; in this model autonomy does not equate to independence. Competence refers to a sense of self-efficacy and accomplishment (Waterman 1993; Vansteenkiste et al. 2009). Relatedness pertains to a desire to feel socially connected to and cared about by others (Ryan and Deci 2002). SDT proposes that humans are intrinsically motivated to pursue activities which satisfy these three basic needs and that this is likely to include pursuits that have the appeal of 'novelty, challenge, or aesthetic value' (Ryan and Deci 2000: 71) - such as the arts.

$<$ Insert Figure 1 here $>$

\section{Methods}




\section{Project background}

To explore arts facilitation in greater detail, this study draws on data gathered as part of Manchester Metropolitan University’s Invest to Save programme. This was a large-scale, mixed-methods research project led by the University (2005-07) in partnership with the Department of Health Public Health Group and Arts Council England, which explored the impact of creative activity on public health (Parkinson 2009). With its focus on arts project facilitation, the current study involved the secondary thematic analysis of fourteen interviews with artists who led projects for older adults and adults with mental health problems in one of three Invest to Save project settings in north-west England.

\section{$<$ Insert Table 1 here $>$}

The artists interviewed specialized in a number of different art forms and had varying degrees of project leadership experience. Some were seasoned practitioners, well known within the sector. Others were recent graduates seeking to develop their skills through shadowing and learning on the job. Most had arts degrees rather than health or social care qualifications.

\section{$<$ Insert Table 2 here $>$}

The interviews were undertaken by members of the original research team using a semistructured format. Interviewees were prompted to talk at length about their professional background, route into community arts/arts for health work, approach to project facilitation and thoughts about the health benefits of arts participation and processes at work. The interviews were then transcribed verbatim with identifying information removed. Resulting 
transcripts were, however, coded, with a corresponding database providing limited, anonymized details about interviewees' project affiliations and fields of practice. Confidentiality was upheld throughout the research process.

\section{Approach to analysis}

Secondary analysis refers to the process of using existing data collected during the course of a prior study to answer a research question or explore an alternative perspective distinct from that of the original work (Heaton 1998). Although relatively commonplace in quantitative research, secondary analysis has rarely been applied to qualitative data (Long-Sutehall et al. 2010). Reasons for this include concerns about misinterpretation and the likely impossibility of member checking to validate findings, as well as ethical considerations around the limitations of consent (Grinyer 2009). Counter to this is a view that secondary analysis offers distinct advantages, not least that bringing multiple perspectives to extant material can yield new insights (Van den Berg 2005), but also a means of fulfilling what might be considered an ethical obligation to maximize data usage (Long-Sutehall et al. 2010). The rationale for revisiting the Invest to Save data presented here was the availability of interview transcripts offering rich insights into artists' experiences which had not previously been analysed systematically or written up for dissemination. In addition, this secondary study involved a couple of researchers who, as members of the original project team, could provide detailed contextual information. Re-analysing these interview transcripts was felt to allow a deeper reflection on the data, enabling the research team to bring to it understandings gained through involvement in arts for health initiatives over the intervening years. It was further noted that the original research was framed using models of eudaimonic well-being and, hence, there was a fit between the dataset and the theoretical approach taken here. Ethical approval for the primary research was obtained through the National Health Service Central Office for 
Research Ethics Committees (COREC). This process encompassed the contracting of partner organizations overseeing participant recruitment as well as the gaining of informed consent from individual participants.

The fourteen transcripts were subject to a thematic analysis using a hybrid method borrowing from the procedures outlined by Attride-Stirling (2001) and Fereday and Muir-Cochrane (2006). The research sought to explore arts facilitation through the lens of SDT, with the analysis therefore guided by an established theory and themes developed both inductively and deductively. The starting point for this process was (re)familiarization with the anonymized transcripts, with two researchers working independently to read the interviews through several times before analysing each data item in turn to establish initial codes. Extracts of data were first highlighted in individual transcripts and subsequently copied and collated in list form in a separate file. After all the data had been initially coded and collated in this way, the next phase involved identifying clusters of codes and organizing them hierarchically into basic and organizing themes. The research team met regularly throughout the process to discuss and agree upon emerging categorizations in relation to individual data extracts and the data set as a whole.

Once there was a consensus that this initial mapping of the dataset was complete and a saturation point had been reached, a theory-led analysis was conducted to interpret and categorize the resultant themes in relation to the three basic psychological needs posited in SDT as defined in the table below. 
This second stage analysis was an iterative process, with organizing themes/themes refined and redefined in order to find the best fit between the dataset and overarching theoretical model. Descriptions and summaries of the basic and organizing themes identified in relation to each of the basic psychological needs are presented below, with interview extracts provided to substantiate points where possible.

\section{Results}

\section{Autonomy overview}

The artists' accounts indicate that they helped to meet participants' autonomy needs through recognizing those taking part to be unique, creative individuals, and empowering them to take control over their participation.

\section{$<$ Insert Table 4 here $>$}

\section{Seeing participants as unique and creative individuals}

The artists talked about looking beyond stereotypes and seeing participants as human beings with distinct interests, opinions and abilities, rather than as patients or service users defined by age, illness or impairment. Several spoke of the originality of the artwork produced, and noted how working with older adults had challenged their preconceptions about the types of activities suitable for this demographic. Examples were cited of participants who had been eager to try out contemporary arts forms and cutting edge and/or complicated techniques. 
Each one of them has their own voice, their own style... The diversity of material is tremendous. (SA 4)

A common observation was that everyone is motivated by different things and that the role of the artist is to prompt a process of self-discovery. It was commented that in an ideal world those taking part would be able to try a range of arts activities to find out what it is that most inspires them. That said, it was also reported that some participants signed up with specific artistic ambitions in mind that had been on hold since childhood.

There are people in my class who have said 'I've always wanted to dance but never given the opportunity'... They are still fulfilling ambitions at a later stage in their lives. (SA 1)

While seeking to identify participants' intrinsic interests, all of the interviewees acknowledged that the arts can provoke anxieties that mask underlying drive. The artists all spoke of creating a supportive and non-judgemental space in which participants would feel able to have a go - to take risks and speak their mind. One way in which this was accomplished was by the artists themselves modelling a playful approach to their own practice. Practitioners spoke of how they would reassure participants that 'mess' was to be expected and there were no 'rights or wrongs'.

With the arts it's not necessarily about right and wrong. It's giving people the techniques or the opportunities to develop things in their own way... You can 
give them help to improve what they're doing but fifty people could have fifty ways or fifty different results... and that's fine (SC 2)

Importantly, there was also a consensus view largely born out of the artists' own experiences that creativity is intimately linked to well-being. Several practitioners spoke of the importance of living fully rather than 'just existing', with art seen as a means to promote selfknowledge and an enhanced self-identity.

A piece of art actually allows you to explore and expand your own identity, and to write it on the world and will help you to understand yourself (SB 5)

\section{Encouraging participants to exert agency over their participation}

Almost all of the artists expressed a desire to see participants assume some control over their participation. In some cases this extended to asking those taking part to input into session planning. Artists further promoted self-directed learning by urging participants to work at their own pace, rather than in competition with others, and to undertake their own work. One interviewee explained how she refrained from stepping in prematurely with help and encouraged participants to decide for themselves when a piece of work was finished. Likewise, others spoke about asking participants to set their own limits in deciding such things as how far to push themselves, how much personal information to disclose, as well as how often to attend. Most of the practitioners took a pragmatic approach to attendance reasoning that older adults should be permitted the freedom to drop in and out of projects/sessions, despite the logistical difficulties this presented. 
I think it's important that they get involved with the curriculum so to speak. It's like a group discussion about where they're at, the type of things they want to do. (SA 3)

Another finding relating to the satisfaction of autonomy needs was the importance artists placed on balancing pre-planned work with more spontaneous participant-initiated activities. It was explained that one of the key skills required of a facilitator is the ability to remain mindful of and responsive to unfolding circumstances and emergent interests. Being flexible, able to improvise and plan 'on the hoof', was also identified as vital to accommodating participants with additional needs who might not be able to access a planned activity; in many cases artists did not know who they would be working with before a session began.

At first I thought 'oh yes, we'll go into a nice poem about this'... and it just doesn't work like that. You'll go in and you'll start talking to somebody and whatever's immediate to them, whatever comes up for them, then you work with that. (SB 3)

\section{Competence overview}

The interviews indicate that artists helped to meet participants' need for a sense of competence by identifying and developing skills and aptitudes, but also repairing negative self-beliefs around artistic abilities. Providing high quality and sufficiently challenging activities was seen as essential to ensuring projects had integrity and remained meaningful for participants. 


\section{Seeing creative ability as universal (while acknowledging individual differences)}

The artists were united in the belief that everyone has some capacity to develop competence within a chosen domain, with a couple expressing surprise at the quality of work produced. At the same time, it was recognized that certain individuals stood out because of their exceptional and sometimes unexpected talents.

One particular lady was a very, very talented artist... the nurses couldn't believe it because she's just a person who sits in a chair and is incontinent and you don't get to know much more about them than that, but she was a really good artist (SB 2)

Despite this, those leading projects also understood that many participants felt insecure in relation to their artistic capabilities, with some disparaging their own work. Blame for this was generally placed on the overly critical nature of older models of arts pedagogy. During the interviews, a number of artists spontaneously reflected on their own feelings of self-doubt and intimidation at various points in their careers. Understanding first hand that the arts can be perceived as elitist and excluding led to an empathetic appreciation of participants' anxieties. This in turn compelled the artists to adopt a more inclusive approach. Indeed, this was one reason many had been drawn to community-based work. 
People can be so excluding; so intimidating. So if you can introduce people to something creative and experiencing that inner support in a safe environment.... It's not intimidating and it's not scary and you can just have a go. (SA 5)

\section{Believing that activities need to be of high quality and challenging}

There was widespread agreement that the arts activities offered needed to be appropriately challenging to be meaningful for participants. All the artists interviewed felt that their own arts-specific skills were at the top of the hierarchy of competencies required to facilitate community arts projects - above interpersonal skills. Several spoke about the need to invest continually in their own creative practice to be effective facilitators. Being able to model a given activity and provide expert input to inspire those taking part was seen as vital to maintaining a project's momentum.

You need to think of yourself as an artist and not an educator I think for this kind of work... so that the projects that you work on are artistic, they have an integrity of their own on whatever level they are produced. (SA 2)

Linked to expert competence was the idea of providing constructive criticism, alongside praise, to extend participants' cognitive, social and/or physical abilities (depending on the art form) and build confidence. Particular value was placed on creative challenges and nudging participants outside their comfort zone through more open-ended, expressive tasks. To this end, several practitioners argued that it was desirable to move beyond familiar craft-based activities to more exploratory and imaginative participant-led work. 
Whenever I find something that's hard for them, I'm like yes! I've found something that's challenging you. And they enjoy it because they come back each week for more. (SA 1)

Many of the artists considered competence acquisition to be at the heart of the transformative power of the arts. Several mentioned their pleasure in witnessing a participant's surprise in relation to unexpected achievements. As with their own arts practice, the acquisition of artsspecific skills was seen as an ongoing process, requiring work and commitment. There was a rejection of the notion of community arts projects as a quick fix solution. One-off and shortterm initiatives were seen as valuable in providing temporary respite for those in difficult circumstances (e.g. a hospital stay) and serving as a springboard to longer-term participation. For this reason, some artists felt that success had been achieved when they saw participants moving on to more advanced courses and established forms of provision.

W has moved on to the learning centre and she's flourishing and she's joined this, that and the other and she's going here and there and everywhere and to a reading class and I think she'll leave [name of charity]. (SA 3)

\section{Relatedness overview}

The interviews reveal that the artists' explicitly understood the centrality of social relationships to the success of projects and sought to meet participants' relatedness needs by cultivating peer-to-peer social interaction in groups, but also though establishing a personal connection to participants themselves. 


\section{Cultivating social interaction within groups}

All of the artists considered social interaction between participants to be a key ingredient in successful arts projects. This was felt to be particularly important in interventions for older people or those who might be socially isolated through disability or ill health. With this in mind, most of the practitioners spoke of setting aside time before, after or during sessions for informal refreshment breaks, with some also arranging additional group get-togethers or outings.

On the social side of things they now always meet early so that they can always have cups of tea and coffee together and we have a Christmas lunch together. (SA 6)

Some artists also talked about nurturing group solidarity in sessions by setting collective challenges or encouraging participants to support one another with tasks. The rewards but also frustrations of arts participation were thought to promote feelings of camaraderie.

Because it's a sort of nice collective activity, so there is a feeling of comradeship. (SA 2)

A couple of artists further referred to the enlivening quality of the arts, observing that the use of sensory rich materials helped stimulate and entice reserved participants to join in. 
You can see people standing on the edge, and then they start to join in and you can see the vibrancy comes to life... Because it's not about it being difficult music or complex music it's about just joining in. (SC 1)

Artists spoke of further promoting peer-to-peer interaction by facilitating group discussions. Most felt that their role was not only to instigate conversation, but also to maintain a warm and non-judgemental atmosphere so that all present might feel encouraged to contribute and listen to different points of view.

I think my role is to facilitate conversation and not give my opinion... I'm after their opinions and experiences... what I'm interested in is their personal take. (SB 1)

\section{Establishing non-hierarchical relationships with participants}

The interviews reveal that the artists themselves also established positive relationship with participants. Rather than adopting the more bounded role of teacher or therapist, many spoke in terms of positioning themselves alongside those taking part as a fellow artist or collaborator.

You know you're not so different from them, you're on an equal level with them really and their contributions are as valid as yours. (SA 2) 
Sometimes this was done on a one-to-one basis to engage individuals who were unable to access the wider social group, due, for example, to communication difficulties, sensory impairment and/or mental or physical health issues.

I think for K [individual with Parkinson's disease], he did enjoy the artistic activity, but along with conversation, and along with everybody getting round the table and the social thing. But he found it very hard to talk within a group because of his speech so we talked to one to one. (SB 4)

It was reported that for some participants the social contact provided by an artist was a major appeal. However, it appears the support on offer was not necessarily all one way. Another artist recollected how participants in a hospital setting had signed up for his project simply because, having seen him struggling to recruit patients, they wanted to help him out.

Maybe I've gone round about ten beds by that time and been told to get lost so I'm looking fairly desperate... people tell me to bugger off and all sorts of things [laughter]... so you can see them thinking, 'oh god help him'. And sometimes people say, 'oh I'm happy to help you'. (SB 5)

Working alongside individuals at difficult times in their lives can inevitably lead to some intense and emotionally charged encounters. Almost all of the artists at some point recalled how they had shared deeply personal moments with participants. Often such incidents related to issues of bereavement or other forms of loss arising in response to the creative work. It is at such times that the practice of arts facilitation perhaps comes closest to that of arts therapy. 
However, the artists interviewed commonly explained they were conscious of their professional limitations and, while aiming to be emotionally supportive of those taking part, generally viewed deeper therapeutic work as beyond their expertise.

One of the most touching things I've ever encountered was a chap who had lost his wife and really that's why he was here... And there was a magic moment when the negative [photographic] image turned into the positive image. And I didn't quite at the moment realise what we'd done, but it was a photograph of his wife when she was very young and he'd not had a photograph of his wife when she was young. (SA 7)

I'm not a therapist... you know I am an artist... I always use this as a watchword... the other person, the patient or whatever you want to call them... they are the ones who say how far we go; I never push. (SB 5)

\section{Wider discussion and conclusions}

Despite increased evidence for the effectiveness of arts and health initiatives, researchers have acknowledged that not enough is known about how different intervention components function to promote well-being (Broderick 2011). There is also a consensus view that shared conceptual frameworks are required to understand the processes mediating arts participation in relation to health outcomes (Stickley et al. 2016; Camic et al. 2016). This study seeks to address these issues by exploring arts practice in health and community settings from the perspective of SDT. More specifically, it provides insights into the varied ways artists satisfy participants' basic needs for autonomy, competence and relatedness and, thereby, help promote psychological well-being. Notably, this was a secondary study and the participants 
in the original study were never specifically asked about, nor expected to have knowledge of, this theoretical framework. However, SDT contends that one does not need to be conscious of basic needs satisfaction in order for outcomes to be in evidence. Individuals (including children) regularly profit from, but also contribute to, psychological need-supportive environments with no or only an intuitive awareness of the processes at work (Grolnick et al. 1984).

Within SDT, autonomy equates to a feeling that behaviour originates from the self in accordance with one's values and interests. Research suggests that autonomy supportive contexts are those where there is scope for self-selected activity and people feel there is a personally meaningful rationale for what they are asked to do (Reeve 2009). The artists in this study were found to help meet participants' autonomy needs by recognizing and respecting differing motivations and tailoring arts practices to the individual. They also enabled those taking part to learn more about themselves and identify intrinsic preferences through involvement in activities fostering self-exploration and/or self-expression. All the artists considered it important to offer a flexible curriculum, inviting participants to exercise choice over project content but also the wider terms of their engagement. This aspiration, that those taking part should assume some ownership over their participation, is consistent with broader person-centred approaches in health and education contexts (O'Hara 1989; Harvey et al. 2002).

A sense of competence refers to feelings of effectiveness and accomplishment. SDT literature indicates that this need is best met in contexts that are well structured and offer optimal levels of challenge (not too easy, but not overwhelming) and constructive feedback (Vansteenkiste et al. 2009). The artists interviewed understood the value of providing stimulating learning 
opportunities and enabling those taking part to gain real-world skills. Many felt that the enhanced confidence and pleasure that stems from competence acquisition in a chosen domain, explains much of the transformative power of the participatory arts. It is worth noting that although this component of basic needs theory is related to Bandura's (1989) notion of self-efficacy, a key distinction is that the latter considers the value of competence to lie in the domain-specific outcomes likely to result. In contrast, basic needs theory suggests it is the experience of competence that is a source of satisfaction and which contributes to feelings of vitality and intrinsic motivation (Ryan and Deci 2000). An important caveat here is that although the artists were united in a belief that everyone has creative potential worth developing, they understood from their own experiences and participants' accounts, that an arts education can thwart feelings of competence and lead to self-criticism. Some of the artists were drawn to leading inclusive projects precisely because helping to repair others' negative self-beliefs helped them too to stay in touch with the more playful, life-affirming aspects of art making.

Relatedness refers to the necessity of warm, trusting and supportive interpersonal relationships, as deemed central to almost all definitions of psychological well-being (Ryan and Deci 2001). Unsurprisingly SDT suggests a need for relatedness is more likely to be met in environments that are warm and responsive rather than cold and neglectful (Vansteenkiste et al. 2009). The artists were most explicit about the importance of satisfying this need, in recognition of the social isolation experienced by many older adults. As a result, they sought to cultivate peer-to-peer social interaction within groups and to forge personal connections with individual participants themselves. Strategies such as scheduling refreshment breaks within sessions and setting collective challenges were cited as ways of engendering a sense of solidarity and belonging. 
Taken together these findings support the idea that there is a compatibility between eudaimonic conceptualizations of well-being, such as is found in SDT, and the participatory arts. Underpinning both is a view of health as more than the absence of illness and a concern for meeting innate drives beyond immediate survival or the striving for pleasure/avoidance of pain. SDT, therefore, is one potential explanatory framework that might permit comparative studies and lead to a deeper understanding of the relationship between arts practices and wellbeing. Unlike other humanistic theories built on the notion of fundamental needs and inherent growth tendencies (e.g. Maslow 1970; Rogers 1961), SDT is supported by a substantial body of empirical studies and a number of well-validated measures (Vallerand et al. 2008). Another advantage from the perspective of arts practitioners is that the theory is not prescriptive: psychological needs are considered innate and universal but it is recognized that their expression is subject to variation across domains, cultures and developmental phases (Ryan and Deci 2000). In other words, SDT does not specify how basic needs could or should be met in any given field, which is pertinent given concerns in some quarters over the standardization, via professionalization, of arts and health practices.

The above comments notwithstanding, it needs to be remembered that project delivery is only one aspect of arts projects contributing to positive outcomes - albeit a significant one. Experimental research indicates that arts projects afford benefits beyond those seen in other control interventions (Cohen et al. 2007; McKinley et al. 2008), which may still be supportive of basic needs. Kelaher et al. (2013: 394) concede that SDT 'is limited in its ability to capture what is unique about the contribution of arts to well-being'. Within this study a question remains over whether basic needs satisfaction is an entirely adequate explanation for the heightened quality of intrinsic motivation - the passion, excitement and 
absorption - described by artists in relation to their own arts practices and as observed in their participants. An alternative standpoint, as expressed in the concept of aesthetic deprivation (Moss and O'Neill 2014) and, indeed, by some of the artists in this research, is that human beings have a fundamental need for aesthetic engagement and creativity in everyday life in order to be fully well. In this reading culture does not just function to meet underlying psychological needs, but also represents the fulfilment of a need in and of itself.

The findings presented are further limited by the size and scale of what was a small, exploratory study focusing on work with older adults. Further research might usefully adopt a larger mixed methods design to examine how replicable the results are across different populations, including projects for children and young people, and in relation to particular art forms and approaches to practice (potentially including arts therapies). It would also be interesting to discover whether, and if so how, artists' own needs for autonomy, competence and relatedness are met or not through the sharing of their creative practice in community and health settings.

\section{Acknowledgements}

Special thanks to the researchers, managers and project participants and staff of the Invest to

Save Arts in Health project (funded by HM Treasury and run by Arts for Health at Manchester Metropolitan University in conjunction with the Department of Health Public Health Group, North West, and Arts Council England, North West): particularly to Amanda Kilroy, Charlotte Garner, Peter Senior and all the artists involved. Further details can be found at: http://www.miriad.mmu.ac.uk/investtosave/. 


\section{References}

Attride-Stirling, J. (2001), 'Thematic networks: An analytic tool for qualitative research', Qualitative Research, 1:3, pp. 385-405.

Bandura, A. (1989), 'Human agency in social cognitive theory', American Psychologist, 44:9, pp. 1175-84.

Berg, H. Van den (2005), 'Reanalyzing qualitative interviews from different angles: The risk of decontextualization and other problems of sharing qualitative data', Forum Qualitative Sozialforschung (Forum: Qualitative Social Research), 6:1, http://www.qualitativeresearch.net/index.php/fqs/article/view/499/1074. Accessed 27 December 2016.

Brett, M., Kuczaj, E. and McHarg, J. (2011), 'Working on the edge: Exploring the role of an art therapist compared to the role of an artist in arts and health contexts - similarities, differences and requirements', Journal of The Irish Association of Creative Arts Therapists, May 2011, http://www.artsandhealth.ie/wp-content/uploads/2011/08/Working-on-the-Edge.pdf. Accessed 27 December 2016.

Broderick, S. (2011), 'Arts practices in unreasonable doubt? Reflections on understandings of arts practices in healthcare contexts', Arts \& Health, 3:2, pp. 95-109. 
Brown, L. (2006), 'Is art therapy? Art for mental health at the millennium', Ph.D., Manchester Metropolitan University, Manchester.

Camic, P. M. (2008), 'Playing in the mud: Health psychology, the arts and creative approaches to health care', Journal of Health Psychology, 13:2, pp. 287-98.

Camic, P. M., Baker, E. L. and Tischler, V. (2016), 'Theorizing how art gallery interventions impact people with dementia and their caregivers', The Gerontologist, 56:6, pp. 1033-1041.

Clennon, O. (2013), 'Two case examples using participatory music as a therapeutic metaphor in a community mental health setting in the United Kingdom', International Journal of Community Music, 6:1, pp. 33-43.

Clift, S. M., Camic, P., Chapman, B., Clayton, G., Daykin, N., Eades, G., Parkinson, C., Secker, J., Stickley, T. and White, M. (2009), 'The state of arts and health in England', Arts \& Health, 1:1, pp. 6-35.

Cohen, G. D., Perlstein, S., Chapline, J., Kelly, J., Firth, K. M. and Simmens, S. (2007), 'The impact of professionally conducted cultural programs on the physical health, mental health, and social functioning of older Adults - 2-year results', Journal of Aging, Humanities, and the Arts, 1:1\&2, pp. 5-22. 
Cole, B. (2011), 'Community music and higher education: A marriage of convenience', International Journal of Community Music, 4:2, pp.79-89.

Creech, A., Hallam, S. and Varvarigou, M. (2012), Facilitating Music-Making for Older People: Facilitator's Handbook: A Continuing Professional Development Resource for Music Leaders, Facilitators and Teachers, London: University of London, http://www.soundsense.org/metadot/index.pl?id=27397\&isa=DBRow\&field name=attachme

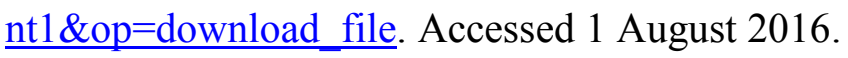

Diener, E. (1984), ‘Subjective well-being’, Psychological Bulletin, 95:3, pp. 542-75.

Dileo, C. and Bradt, J. (2009), 'On creating the discipline, profession, and evidence in the field of arts and healthcare', Arts \& Health, 1:2, pp. 168-82.

Fereday J. and Muir-Cochrane, E. (2006), 'Demonstrating rigor using thematic analyis: A hybrid approach of inductive and deductive coding and theme development', International Journal of Qualitative Methods, 5:1, pp. 1-11.

Gagné, M. and Deci, E. L. (2005), 'Self-determination theory and work motivation', Journal of Organizational Behavior, 26:4, pp. 331-62. 
Grinyer, A. (2009), 'The ethics of the secondary analysis and further use of qualitative data', Social Research Update, 56, http://sru.soc.surrey.ac.uk/SRU56.pdf. Accessed 4 August 2016.

Grolnick, W., Frodi, A. and Bridges, L. (1984), 'Maternal control style and the mastery motivation of one-year-olds', Infant Mental Health Journal, 5:2, pp. 72-82.

Harvey, G., Loftus-Hills, A., Rycroft-Malone, J., Titchen, A., Kitson, A., McCormack, B. and Seers, K. (2002), 'Getting evidence into practice: The role and function of facilitation', Journal of Advanced Nursing, 37:6, pp. 577-88.

Heaton, J. (1998), 'Secondary analysis of qualitative data', Social Research Update, 22, http://sru.soc.surrey.ac.uk/SRU22.html. Accessed 4 August 2016.

Higgins, L. (2008), 'The creative music workshop: Event, facilitation, gift', International Journal of Music Education, 26:4, pp. 326-38.

Horne, M. (2016), 'Care to Dance: Listening, watching, dancing and reflecting the practice of a community arts and health Dance artist working with older people', Ph.D., Manchester Metropolitan University, Manchester. 
Hughes, J. (2005), Doing the Arts Justice: A Review of Research Literature, Practice and Theory, Manchester: Arts Council England, Department for Culture, Media \& Sport, Department for Education and Skills, Unit for the Arts and Offenders.

http://webarchive.nationalarchives.gov.uk/+/http:/www.culture.gov.uk/NR/rdonlyres/D4B44 5EE-4BCC-4F6C-A87A-C55A0D45D205/0/Doingartsjusticefinal.pdf. Accessed 4 August 2016.

Kelaher, M., Dunt, D., Berman, N., Curry, S., Joubert, L. and Johnson, V. (2013), 'Evaluating the health impacts of participation in Australian community arts groups', Health Promotion International, 29:3, pp. 392-402.

Kelaher, M., Dunt, D., Berman, N., Joubert, L., Curry, S., Jones, R., et al. (2007), 'Methodological approaches to evaluating the impact of community arts on health', UNESCO Observatory, Multi-Disciplinary Research in the Arts, 1, pp. 1-18.

Keyes, C. L. M., Shmotkin, D. and Ryff, C. D. (2002), 'Optimizing well-being: The empirical encounter of two traditions', Journal of Personality and Social Psychology, 82:6, pp. 1007-22.

Lawthom, R., Sixsmith, J. and Kagan, C. (2007), 'Interrogating power: The case of arts and mental health in community projects', Journal of Community \& Applied Social Psychology, 17:4, pp. 268-79. 
Lith, T. Van, Fenner, P. and Schofield, M. (2009), 'Toward an understanding of how art making can facilitate mental health recovery', Advances in Mental Health, 8:2, pp. 183-93.

Long-Sutehall, T., Sque, M. and Addington-Hall, J. (2010), 'Secondary analysis of qualitative data: A valuable method for exploring sensitive issues with an elusive population?', Journal of Research in Nursing, 16:4, pp. 335-44.

Maslow, A. (1970), Motivation and Personality, 2nd ed., New York: Harper \& row.

McGregor, I. and Little, B. (1998), 'Personal projects, happiness, and meaning: On doing well and being yourself', Journal of Personality and Social Psychology, 74:2, pp. 494-512.

McKinley, P., Jacobson, A., Leroux, A., Bednarczyk, V., Rossignol, M. and Fung, J. (2008), 'Effect of a community-based Argentine Tango dance program on functional balance and confidence in older adults', Journal of Aging and Physical Activity, 16:4, pp. 435-53.

Moss, H. and O’Neill, D. (2009), 'What training do artists need to work in healthcare settings?', Medical Humanities, 35:2, pp. 101-05.

(2014), 'Aesthetic deprivation in clinical settings', The Lancet, 383:9922, pp. 1032-33. 
O’Hara, M. (1989), 'When I use the term humanistic psychology', Journal of Humanistic Psychology, 29:2, pp. 263-73.

Parkinson, C. (2009), 'Invest to Save: Arts in health - reflections on a 3-year period of research and development in the North West of England', Australasian Journal of ArtsHealth, 1, pp. 40-60.

Price, D. (2010), 'A view from the workshop floor: What skills and qualities are demanded of today's community music workers and how can they best be taught?', International Journal of Community Music, 3:3, pp. 331-36.

Raw, A. (2013), 'A model and theory of community-based arts and health practice', Ph.D., University of Durham, Durham.

Reeve, J. (2009), 'Why teachers adopt a controlling motivating style toward students and how they can become more autonomy supportive', Educational Psychologist, 44:3, 159-75.

Rogers, C. (1961), On Becoming a Person: A Therapist's view of Psychotherapy, 16th ed., Boston: Houghton Mifflin Company. 
Ryan, R. and Deci, E. (2000), 'Self-determination theory and the facilitation of intrinsic motivation, social development, and well-being', American Psychologist, 55:1, pp. 68-78.

(2001), 'On happiness and human potentials: A review of research on hedonic and eudaimonic well-being', Annual Review of Psychology, 52:1, pp. 141-66.

(eds) (2002), 'Overview of self-determination theory: An organismic dialectical perspective', in Handbook of Self-Determination Research, Rochester: University of Rochester Press, pp. 3-33.

Ryan, R. and Fredrick, C. (1997), 'On energy, personality, and health: Subjective vitality as a dynamic reflection of well-being', Journal of Personality, 65:3, pp. 529-65.

Stickley, T., Parr, H., Daykin, N., Clift, S., De Nora, T., Hacking, S., Camic, P., Joss, T., White, M. and Hogan, S. (2016), 'Arts, health \& wellbeing: Reflections on a national seminar series and building a UK research network', Arts \& Health, pp. 1-12. doi:10.1080/17533015.2016.1166142

Swindells, R., Lawthom, R., Rowley, K., Siddiquee, A., Kilroy, A. and Kagan, C. (2013), 'Eudaimonic well-being and community arts participation', Perspectives in Public Health, $133: 1$, pp. 60-65. 
Vallerand, R., Pelletier, L. and Koestner, R. (2008), 'Reflections on self-determination theory', Psychologie canadienne (Canadian Psychology), 49:3, pp. 257-62.

Vansteenkiste, M., Sierens, E., Soenens, B., Luyckx, K. and Lens, W. (2009), 'Motivational profiles from a self-determination perspective: The quality of motivation matters', Journal of Educational Psychology, 101:3, pp. 671-88.

Veblen, K. (2009), 'The facilitraining rainbow: An interview with Phil Mullen', International Journal of Community Music, 2:2, pp. 263-65.

Waterman, A. S. (1993), 'Two conceptions of happiness: Contrasts of personal expressiveness (eudaimonia) and hedonic enjoyment', Journal of Personality and Social Psychology, 64:4, pp. 678-91.

White, M. (2006), 'Establishing common ground in community-based arts in health', The Journal of the Royal Society for the Promotion of Health, 126:3, pp. 128-33.

\section{Contributor details}

Rachel Swindells is a researcher in the Social Change and Community Wellbeing Centre at Manchester Metropolitan University. She has an academic background in ethnomusicology and psychology and previously led the Hallé Orchestra's gamelan programme for several 
years. Her research interests include Sundanese gamelan, cross-cultural/genre approaches to music learning, music and dis/ability, and theorizing well-being in relation to the arts.

Rebecca Lawthom is Professor of Community Psychology and heads the Centre of Social Change and Community Wellbeing at Manchester Metropolitan University. She is a community psychologist who works with those marginalized by the social system. She works in partnership with community partners and has expertise in disability, feminism and migration. She is one of the editors of the Community Work and Family journal.

Clive Parkinson is the Director of Arts for Health at Manchester Metropolitan University, a specialist research unit exploring the relationship between creativity, culture, the arts and health. He is Reader at the Manchester School of Art and a founding member of the National Alliance for Arts, Health and Wellbeing, and is currently a co-investigator on the Dementia \& Imagination project in the United Kingdom. His public health interest is focused on social justice and inequalities and the unexpected outcomes of arts engagement. He regularly blogs at: http://artsforhealthmmu.blogspot.co.uk/.

Ornette Clennon is a Visiting Research Fellow and critical race scholar at Manchester Metropolitan University where he leads the Critical Race and Ethnicity Research Cluster. 
Carolyn Kagan (Professor Emerita, Manchester Metropolitan University) is a community psychologist who has worked for many years with people who are marginalized by the social system on participative action research projects. She is interested in the intersections of art, creativity, community well-being and social change. She is in the Editorial Board of the international journal Arts and Health.

Christophe de Bézenac is postdoctoral researcher in cognitive neuroscience at the University of Liverpool with a particular interest in the dynamics of social interaction. He is also a musician involved in the European jazz scene and previously lectured in music at a number of higher education institutions. Christophe has recently led a number of art-science collaborations that integrate brain scanning and real-time audio-visual processing into multimedia art installations.

Contact:

Rachel Swindells, Rebecca Lawthom, Ornette Clennon and Carolyn Kagan, Faculty of Health, Psychology \& Social Care, Manchester Metropolitan University, Brooks Building, 53 Bonsall Street, Manchester, M15 6GX, UK.

E-mail: rachelswindells@yahoo.co.uk

E-mail: r.lawthom@mmu.ac.uk

E-mail: $\underline{\text { o.clennon@mmu.ac.uk }}$

E-mail: c.kagan@mmu.ac.uk 
Clive Parkinson, Manchester School of Art, Righton Building Room 116, Cavendish Street, Manchester M15 6BG, UK.

E-mail: c.parkinson@mmu.ac.uk

Christophe de Bézenac, Institute of Psychology, Health \& Society, University of Liverpool, 2nd Floor Block B Waterhouse Buildings, 1-5 Brownlow Street, Liverpool, L69 3GL, UK. E-mail: cedb@liverpool.ac.uk

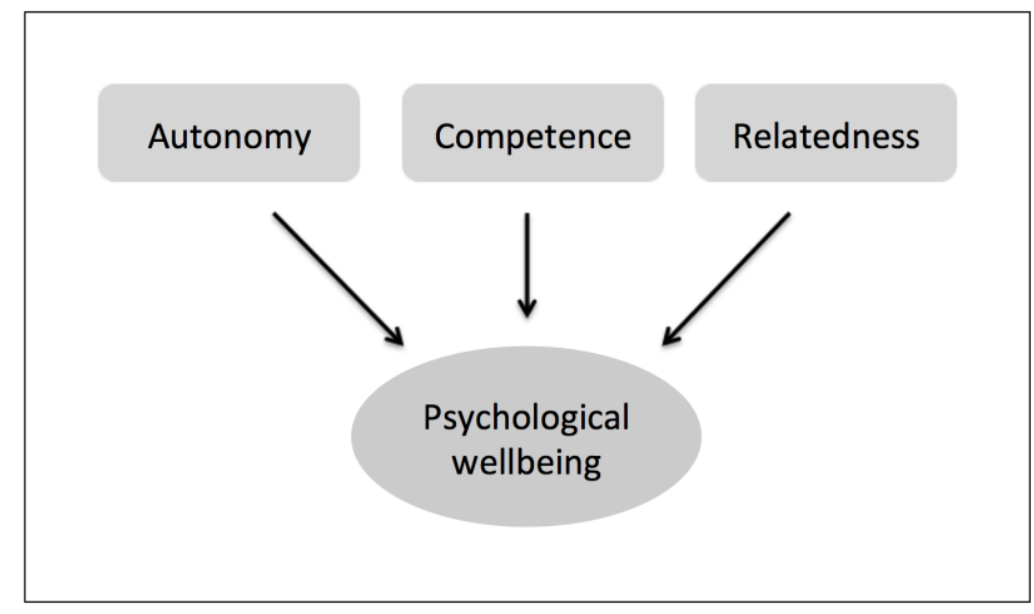

Figure 1: Basic needs for psychological well-being. 


\begin{tabular}{|l|l|l|}
\hline \multicolumn{2}{|l|}{ Invest to Save project settings } \\
\hline Setting & Code & Description \\
\hline Setting A & SA & Community arts scheme run in conjunction with a national \\
& & $\begin{array}{l}\text { charity to promote positive ageing and reduce social } \\
\text { isolation for people aged over 55 }\end{array}$ \\
\hline Setting B & SB & $\begin{array}{l}\text { Initiative providing creative activities to promote } \\
\text { psychological well-being for older adults in hospital and } \\
\text { rehabilitation care (50 per cent over 85 years) }\end{array}$ \\
& SC & Scheme offering opportunities for creative learning and \\
& socialization for adults diagnosed with depression (the \\
& majority of participants were aged 55 or over) \\
\hline
\end{tabular}

Table 1: Invest to Save project settings. 


\begin{tabular}{|c|c|c|}
\hline \multicolumn{3}{|c|}{ Invest to save - artists interviewed } \\
\hline Setting & $\begin{array}{l}\text { Participant } \\
\text { code }\end{array}$ & Arts specialism \\
\hline \multirow[t]{7}{*}{ Setting A } & SA 1 & Dance \\
\hline & SA 2 & Music/song-writing \\
\hline & SA 3 & Visual arts and textiles \\
\hline & SA 4 & Poetry/creative writing \\
\hline & SA 5 & Visual arts \\
\hline & SA 6 & Drama/theatre \\
\hline & SA 7 & $\begin{array}{l}\text { Design, illustration, } \\
\text { photography }\end{array}$ \\
\hline \multirow[t]{5}{*}{ Setting B } & SB 1 & Visual arts \\
\hline & SB 2 & $\begin{array}{l}\text { Visual arts, printmaking, } \\
\text { poetry }\end{array}$ \\
\hline & SB 3 & $\begin{array}{l}\text { English, creative writing, } \\
\text { drama }\end{array}$ \\
\hline & SB 4 & Ceramics \\
\hline & SB 5 & Poetry, creative writing \\
\hline \multirow[t]{2}{*}{ Setting C } & $\mathrm{SC} 1$ & Music \\
\hline & SC 2 & Drama, theatre \\
\hline
\end{tabular}

Table 2: Artists' specialisms and project affiliation. 


\begin{tabular}{|l|l|}
\hline \multicolumn{2}{|l|}{ Basic psychological needs } \\
\hline Autonomy & -Experience of freedom, choice, volition; not feeling controlled \\
& -Feeling that behaviour originates from the self - pursuing intrinsic \\
& interests, self-identified and self-endorsed goals; not acting due to \\
& external pressures, rewards or expectations \\
& - -Sense of authenticity and self-identity \\
\hline Competence & $\begin{array}{l}\text {-Feeling purposeful, effective, a sense of mastery or accomplishment in } \\
\text { one's behaviour; not feeling incompetent, ineffective or under } \\
\text { stimulated/challenged }\end{array}$ \\
\hline Relatedness & $\begin{array}{l}\text {-Sense of belonging and meaningful connection to others; not feeling } \\
\text { alienated, lonely or ostracized }\end{array}$ \\
\hline
\end{tabular}

Table 3: Definitions of basic psychological needs used in deductive coding. 


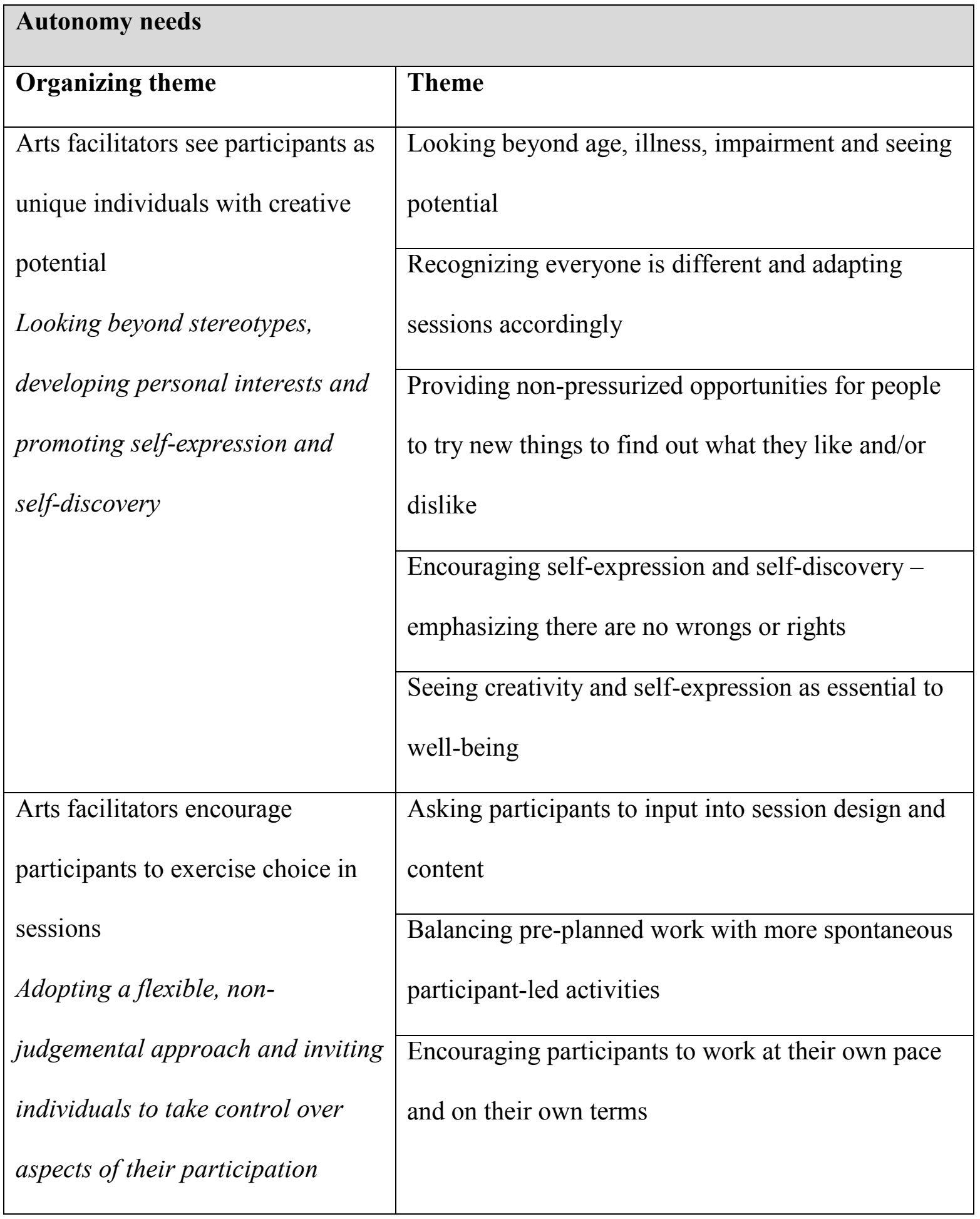

Table 4: Overview of autonomy results. 


\begin{tabular}{|c|c|}
\hline Competence needs & \\
\hline Organizing theme & Theme \\
\hline $\begin{array}{l}\text { Arts facilitators see creative ability } \\
\text { as universal (while acknowledging } \\
\text { difference) } \\
\text { Considering everyone to have } \\
\text { artistic potential but recognizing } \\
\text { that economic and sociocultural } \\
\text { factors limit access to the arts and } \\
\text { undermine confidence }\end{array}$ & $\begin{array}{l}\text { Recognizing that participants' may feel discouraged } \\
\text { and repairing negative self-beliefs }\end{array}$ \\
\hline $\begin{array}{l}\text { Arts facilitators suggest that arts } \\
\text { activities need to present a degree } \\
\text { of challenge to be meaningful } \\
\text { Seeing their role as providing } \\
\text { creative input and guidance, } \\
\text { setting high expectations and } \\
\text { providing praise and constructive } \\
\text { criticism }\end{array}$ & $\begin{array}{l}\text { Believing arts activities need to be high quality and } \\
\text { challenging to be meaningful } \\
\text { Viewing their own artistic competencies as key to } \\
\text { project integrity } \\
\text { Devising tasks that offer appropriate levels of } \\
\text { challenge } \\
\text { Seeing creative challenges as of particular value } \\
\text { Considering the development of artistic } \\
\text { competencies to be a long-term endeavour to be of } \\
\text { maximum benefit }\end{array}$ \\
\hline
\end{tabular}

Table 5: Overview of competence results. 


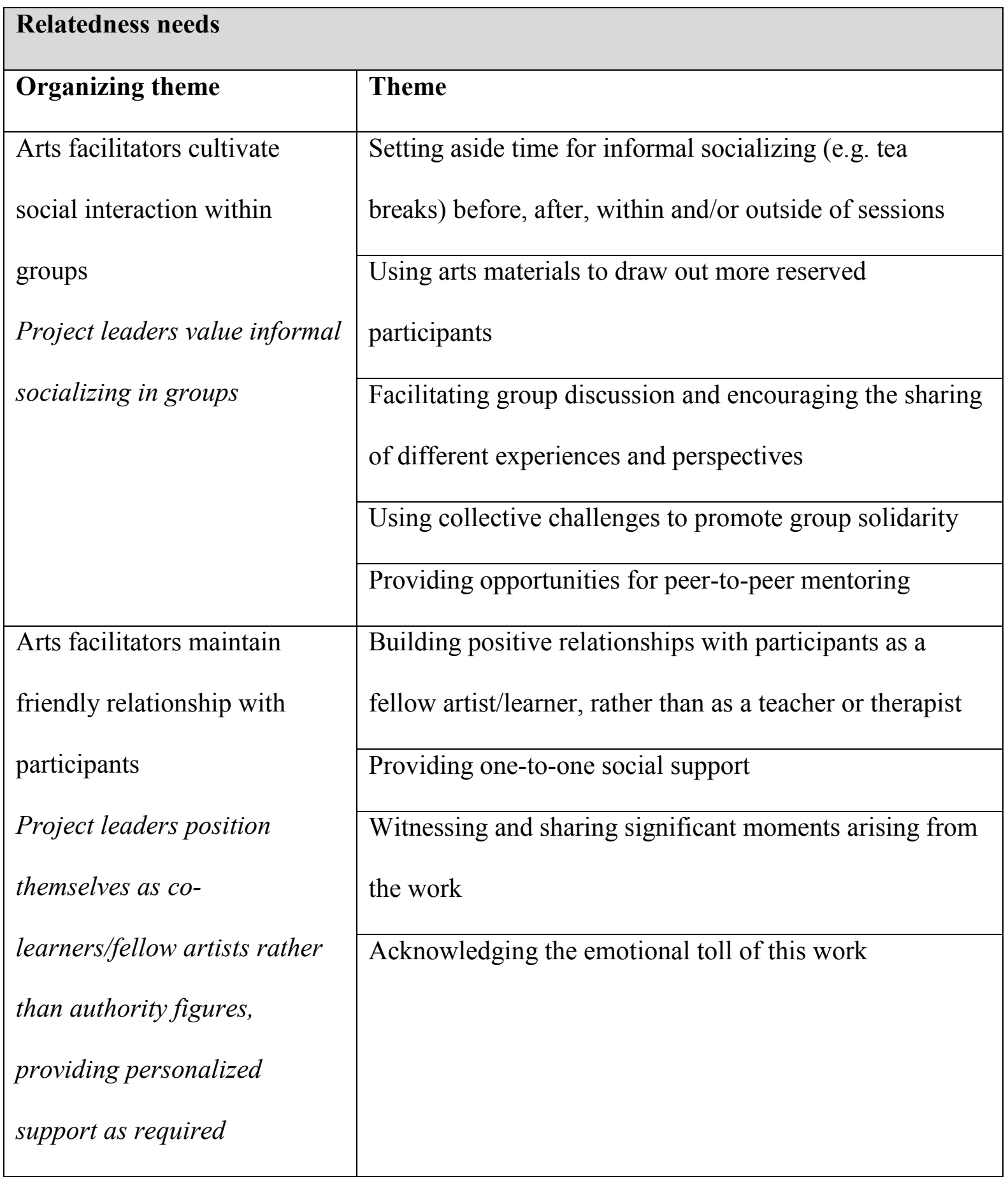

Table 6: Overview of relatedness results. 